\title{
Two-Stage Directed Self-assembly of a Cyclic [3]Catenane
}

\author{
Christopher S. Wood ${ }^{1}$, Tanya K. Ronson ${ }^{1}$, Ana M. Belenguer ${ }^{1}$, Julian J. Holstein ${ }^{2 \dagger}$, Jonathan \\ R. Nitschke ${ }^{1 *}$ \\ ${ }^{1}$ Department of Chemistry, University of Cambridge, Lensfield Road, Cambridge, CB2 1EW, UK \\ ${ }^{2}$ Global Phasing Ltd., Sheraton House, Castle Park, Cambridge CB3 OAX, UK \\ ${ }^{\dagger}$ Current address: GZG, Abteilung Kristallographie, Georg-August-Universität Göttingen, Goldschmidtstr. 1, \\ 37077 Göttingen, Germany \\ *e-mail: jrn34@cam.ac.uk
}

TOC Graphic

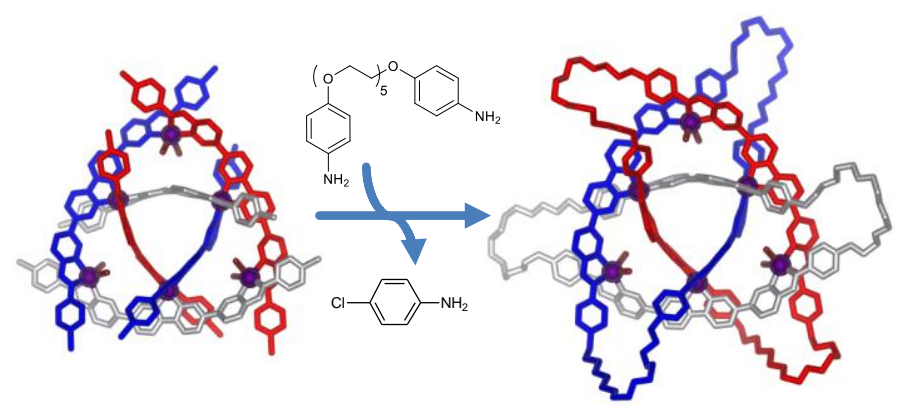

TOC Summary

A cyclic [3]catenane was prepared in two stages via a selective imine exchange reaction upon a self-assembled triangular precursor.

\begin{abstract}
Interlocked molecules possess properties and functions that depend upon their intricate connectivity. In addition to the topologically trivial rotaxanes, whose structures may be captured by a planar graph, the topologically non-trivial knots and catenanes represent some of chemistry's most challenging synthetic targets because their non-planar graphs require three-dimensional assembly instructions to be supplied. Here we report the synthesis of a cyclic [3]catenane, which consists of three mutually interpenetrating rings, via an unusual synthetic route. Five distinct building blocks self-assemble into a heteroleptic triangular framework composed of two joined $\mathrm{Fe}^{\mathrm{II}}{ }_{3} \mathrm{~L}_{3}$ circular helicates.
\end{abstract}


Subcomponent exchange then allowed specific points in the framework to link together to generate the cyclic [3]catenane product. Our method represents an advance both in the intricacy of the metal-templated self-assembly procedure and in the use of selective imine exchange to generate a topologically complex product.

Some of the most complex objects of synthetic chemistry that have been prepared to date have intricate interlocked molecular topologies, such as knots, links and catenanes. ${ }^{1-4}$ The precise intertwining of molecular subunits has been shown to allow access to new properties, such as directed molecular motion ${ }^{5}$ and novel forms of chirality. ${ }^{6}$ In nature there is a strong link between topology and function, with natural examples of functional interlocked topologies being found in DNA, ${ }^{7}$ proteins ${ }^{8,9}$ and the chainmail-like structure of the capsid of virus HK97. ${ }^{10}$ Synthetic chemists have exploited topology to create molecular machines and other devices. ${ }^{1}$ More complex link or knot topologies remain attractive targets, as it has been observed that knotting affects the properties of synthetic polymers. ${ }^{11,12}$

The syntheses of interlocked structures can be broken down into elementary steps, where the final ring-closing step to form the knot or catenane must be preceded by pre-organisation of the components. Sauvage et al. pioneered the use of metal-ligand interactions to preorganise ligands around metal ions to program crossing points in order to synthesise topologically non-trivial structures, such as [2]catenanes and a trefoil knot. ${ }^{13}$ This preorganisation can also be promoted by other templation effects using supramolecular interactions, such as $\pi$ donoracceptor interactions ${ }^{14}$ and hydrogen bonds ${ }^{15}$ or through use of the hydrophobic effect in water. $^{3,4}$ The final ring-closing step can be completed using either kinetically-controlled ${ }^{16}$ or thermodynamically-controlled ${ }^{4,17-19}$ reactions. Other methods, where both templation and mechanical interlocking occur in a one pot reaction, such as metal-templated imine condensation, ${ }^{20}$ and 'active metal template' reactions ${ }^{3}$ have also been fruitfully developed. As supramolecular synthetic methods have increased in sophistication, so too have the scaffolds available for knotting increased in structural complexity. A case in point is the recent syntheses of a pentafoil knot and Star of David catenane by Leigh et al., ${ }^{19,21}$ which were built using principles uncovered during the preparation of Lehn's pentanuclear and hexanuclear circular helicates. ${ }^{22} \mathrm{~A}$ feature in the syntheses of these interlocked architectures is the need to 
program a high level of structural complexity into the precursor framework before the mechanical interlocking step.

\section{Results and discussion}

Here we report the preparation of a new cyclic [3]catenane, a chiral assembly of three mutually interpenetrating rings. The underlying framework of this [3]catenane was constructed through an intricate metal-templated self-assembly procedure, which involved five distinct precursors, to generate a mixed-ligand circular double helicate. The design of this framework allowed for the subsequent mechanical interlocking of specific sites to form the cyclic [3]catenane product.

As shown in Fig. 1, the self-assembly of mixed-ligand circular double helicate $\mathbf{1}$ involved the in-situ generation of ligands $\mathbf{L}^{\mathbf{A}}$ and $\mathbf{L}^{\mathbf{B}}$ from their precursor subcomponents $\mathbf{A}, \mathbf{B}$ and 4chloroaniline. These subcomponents came together around iron(II) templates in acetonitrile, with bromide anions completing the octahedral coordination spheres of the outermost iron(II) centres. Single crystal X-ray analysis revealed the solid-state structure of $\mathbf{1}$ (Fig. $1 \mathrm{~b}$ and 1c) to be consistent with solution measurements taken by both Electrospray Ionization Mass Spectrometry (ESI-MS) and Nuclear Magnetic Resonance (NMR, discussed below). The architecture of $\mathbf{1}$ consists of two interwoven trinuclear circular helicates, linked by coordination of the three iron(II) centres in the inner $\mathrm{Fe}_{3} \mathbf{L}_{3}^{\mathbf{B}}$ triangle to the three central bipyridine sites of ligand $\mathbf{L}^{\mathbf{A}}$ in the outer $\mathrm{Fe}_{3} \mathbf{L}^{\mathbf{A}}{ }_{3}$ triangle. The structure is further stabilised by $\pi$-stacking interactions between the 4-chloroaniline residues of $\mathbf{L}^{\mathbf{B}}$ and the central bipyridine rings of $\mathbf{L}^{\mathbf{A}}$ with centroid-centroid distances of 3.42-4.01 $\AA$. The six iron(II) centres in $\mathbf{1}$ are roughly coplanar and the complex possesses approximate $D_{3}$ point symmetry (Fig. 1). 

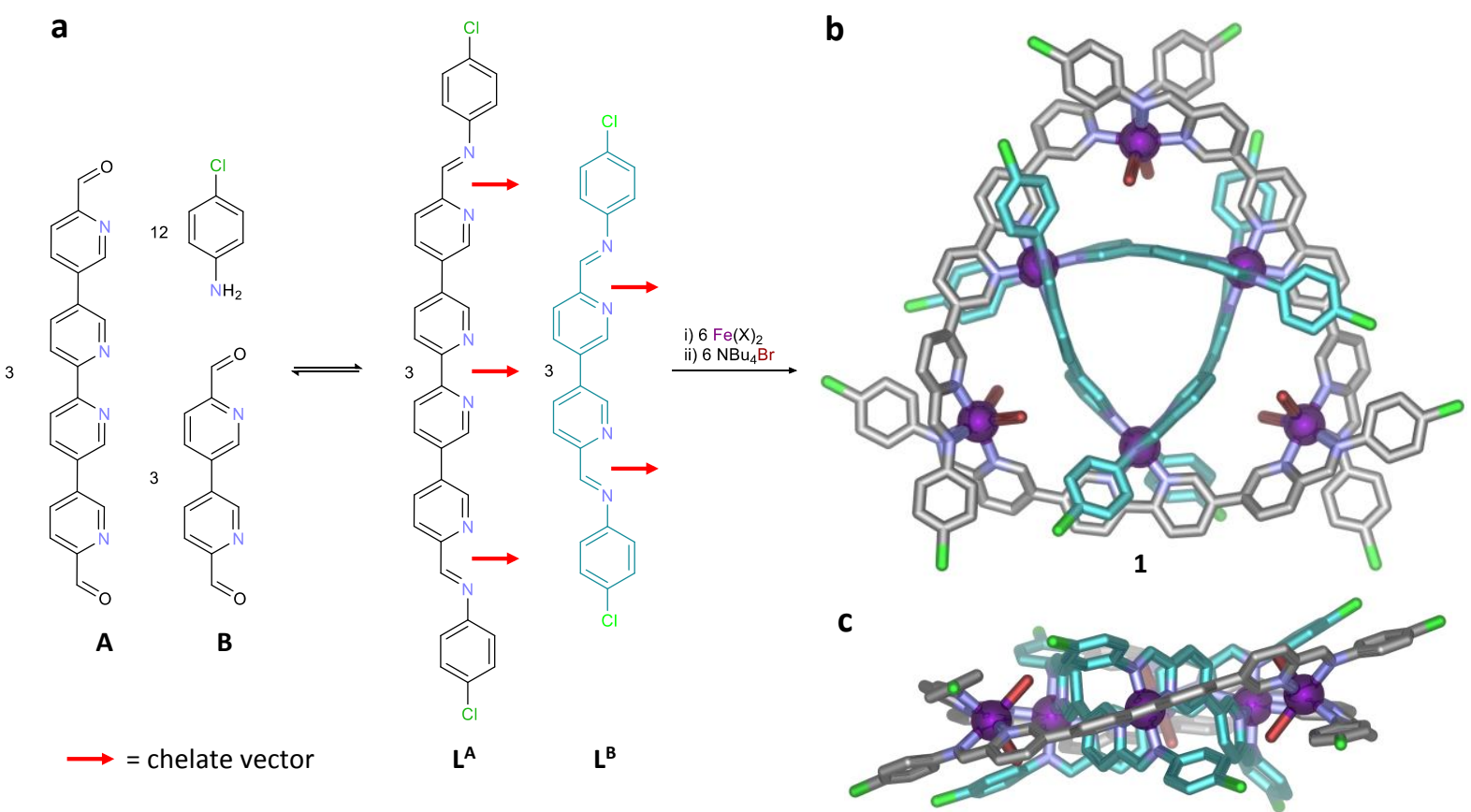

Figure 1 | Synthesis and X-ray crystal structure of mixed-ligand circular double helicate

1. (a) Ligands $\mathbf{L}^{\mathbf{A}}$ and $\mathbf{L}^{\mathbf{B}}$ formed from subcomponents $\mathbf{A}$ and $\mathbf{B}$. $\mathbf{L}^{\mathbf{A}}$ was designed with 3 rigidly-held parallel chelate vectors to favour the formation of mixed-ligand architectures. (b) view down a threefold axis of symmetry (c) view down a twofold axis. Hydrogen atoms, noncoordinated anions and solvent are omitted for clarity (C: grey $\mathbf{L}^{\mathbf{A}}$ or turquoise $\mathbf{L}^{\mathbf{B}}, \mathrm{N}$ : blue, $\mathrm{Br}$ : brown, $\mathrm{Fe}$ : purple, $\mathrm{Cl}$ : green). $\mathrm{X}=\mathrm{BF}_{4}{ }^{-}$or $\mathrm{ClO}_{4}{ }^{-}$.

The bromide ligands act to satisfy the octahedral coordination preference of the iron(II) centres at the corners of the larger helicate. The low ligand strength of bromide stabilised the high-spin state of these iron(II) centres, causing the complex to exhibit paramagnetism as observed in the ${ }^{1} \mathrm{H}$ NMR spectrum (Supplementary Information Section 1.6). The inner iron(II) centres, in contrast, were observed in the low-spin state due to their higher-strength $\mathrm{FeN}_{6}$ ligand environment. The Fe-N bond lengths are in the range 1.960(4)-1.997(4) $\mathrm{A}$ for the inner iron(II) centres and 2.147(4)-2.304(5) $\AA$ for the outer iron(II) centres; these values are consistent with their respective low- and high-spin states at $100 \mathrm{~K}$.

The architecture of $\mathbf{1}$ was observed to form when other coordinating anions (e.g. $\mathrm{Cl}^{-}$and $\mathrm{SCN}^{-}$) were used in place of bromide and when other anilines (e.g. 4-toluidine and 4anisidine) were used in place of 4-chloroaniline. However, we did not observe discrete 
species to form when the primary aliphatic amines benzylamine and 2-methoxyethylamine were used in place of an aniline; we infer this may be due to a combination of unfavourable steric effects and the absence of favourable $\pi$-stacking interactions when these amines are employed. Single crystal X-ray analysis of the $\mathrm{Cl}^{-}$and $\mathrm{SCN}^{-}$derivatives (Supplementary Information Section 3) confirmed they shared a common architecture with $\mathbf{1}$. No combination of aniline and coordinating anion was found to generate the architecture of $\mathbf{1}$ where all iron(II) centres exist in a low-spin state, with insoluble precipitates being formed when higher ligand field strength anions (e.g. $\mathrm{F}^{-}$) were employed.

Five distinct building blocks thus self-assembled to form mixed-ligand circular helicate ${ }^{23} \mathbf{1}$ in solution. Crucially no homoleptic species of either ligand were detected by ESI-MS or ${ }^{1} \mathrm{H}$ NMR spectroscopy. In most cases where multiple different ligands are used in concert, selfsorting occurs, resulting in the formation of two or more discrete homoleptic species. ${ }^{24,25}$ In the present case, we were able to avoid self-sorting through the design of ligand $\mathbf{L}^{\mathbf{A}}$.

During the design of self-assembled structures using metal coordination, the principle of coordinative saturation is often employed as a first-order construction principle. This principle holds that the smallest structure will be formed in which all ligand binding sites (nitrogen atoms, here) and all metal coordination sites will be bound together. ${ }^{26}$ This approach resulted in the self-assembly of unstrained $\mathrm{M}_{4} \mathrm{~L}_{6}$ tetrahedra and $\mathrm{M}_{10} \mathrm{~L}_{15}$ pentagonal prisms ${ }^{27}$ when previously reported subcomponent B reacted with octahedral metal ions.

To favour the formation of mixed-ligand structures, we therefore considered the principle of coordinative saturation applied across the whole system. ${ }^{28}$ Mixed-ligand species in which all potential coordination sites are satisfied would be favoured if one or more of the ligands could not form discrete unstrained homoleptic structures. ${ }^{29}$ Ligand $\mathbf{L}^{\mathbf{A}}$ was designed to have complimentary inter-binding-site distances to ligand $\mathbf{L}^{\mathbf{B}}$. The three binding sites (red arrows in Fig. 1) are held rigidly parallel to one another precluding the formation of a discrete unstrained structure containing only $\mathbf{L}^{\mathbf{A}}$ and six-coordinate metal ions (such as $\mathrm{Fe}^{\mathrm{II}}$ ). Indeed, no discrete species were observed in either the ESI-MS or ${ }^{1} \mathrm{H}$ NMR spectra when $\mathbf{L}^{\mathbf{A}}$ was combined with iron(II) salts in acetonitrile. 
However, together with equimolar amounts of $\mathbf{L}^{\mathbf{B}}, \mathbf{L}^{\mathbf{A}}$ is able to coordinate to iron(II) to form the central triangle of circular helicate 1 without significant strain. This geometry places the terminal coordination sites of $\mathbf{L}^{\mathbf{A}}$ in close proximity to each other, enabling the chelation of additional iron(II) ions in these sites. Coordinating anions - bromide in the case of $\mathbf{1}$ - serve to cap the vacant coordination sites of these outer iron(II) centres.

The proximity and the orientations of the 4-chloroaniline residues within the structure of $\mathbf{1}$ led us to hypothesise that pairs of these residues could be selectively replaced through the addition of a diamine (Fig. 2). Although one could envisage linkage between different potential connection sites within $\mathbf{1}$, control over diamine length and geometry permitted the two closest metal-coordinated imine sites on the same face to be selectively linked.

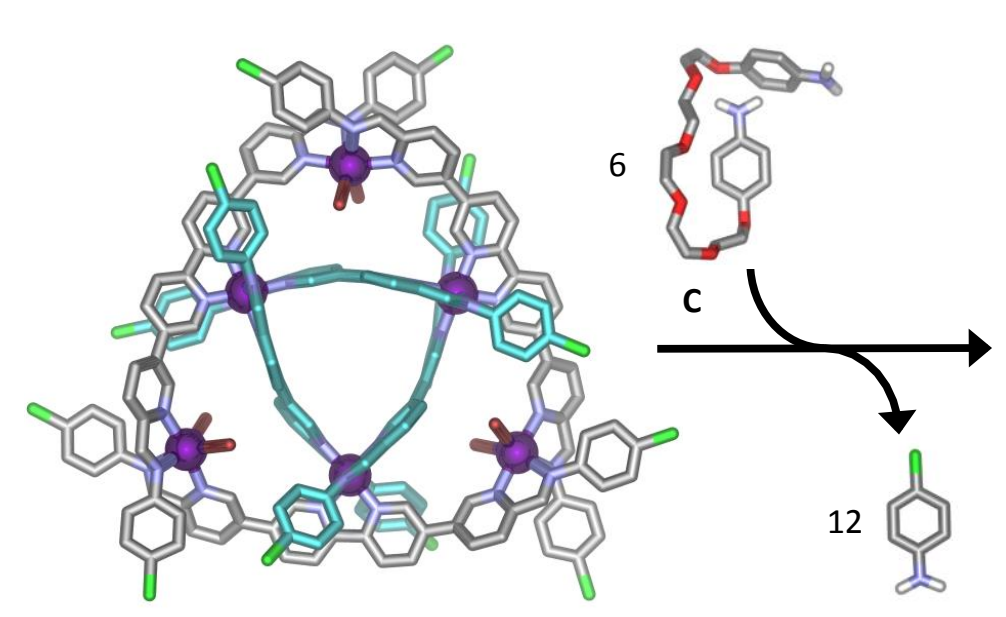

1

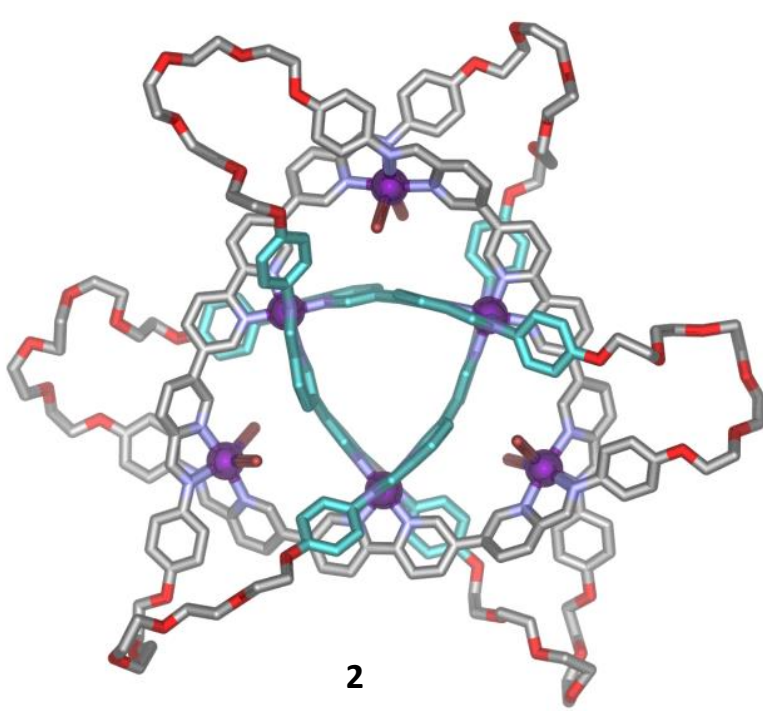

Figure 2 | Subcomponent substitution of 1 with diamine $\mathbf{C}$ yielded cyclic [3]catenane 2, shown as the crystal structure. Six equivalents of electron-rich diamine $\mathbf{C}$ replace twelve equivalents of electron-poor 4-chloroaniline, while retaining the geometry of $\mathbf{1}$ to yield the mechanically interlocked cyclic [3] catenane 2. Hydrogen atoms, disorder, non-coordinated anions and solvent are omitted for clarity (C: grey or turquoise, $\mathrm{N}$ : blue, $\mathrm{O}$ : red, Br: brown, Fe: purple, $\mathrm{Cl}$ : green).

Preliminary molecular modelling studies suggested that an optimal length of dianiline would be provided by the pentaethylene glycol chain of bis-para-substituted dianiline $\mathbf{C}$. However, 
studies on $\mathbf{C}$ and a range of flexible and rigid diamines using a one-pot synthesis method, ${ }^{2}$ whereby all the building blocks were combined directly, led to the formation of insoluble materials, which we inferred to be cross-linked polymers. We therefore devised a method of mechanically interlocking the ligands based on subcomponent substitution, whereby electronrich anilines displace electron-poor aniline residues ${ }^{30}$ (in this case 4-chloroaniline) whilst maintaining the complex geometry of the self-assembled precursor framework $\mathbf{1}$.

The reaction of $\mathbf{1}$ with dianiline $\mathbf{C}$ (6.5 equiv.) and $\mathrm{NaBr}$ (1 equiv.) in acetonitrile led to the formation of metal-organic cyclic [3] catenane 2 after heating at $70{ }^{\circ} \mathrm{C}$ for five days. ESI-MS confirmed that the complete substitution of twelve 4-chloroaniline residues in favour of six dianilines had occurred. The addition of $\mathrm{NaBr}$ or other alkaline metal salts (Supplementary Information section 1.13) was found to be necessary for the clean formation of the cyclic [3]catenane. We hypothesise that $\mathrm{Na}^{+}$acts to preorganise the dianiline through complexation of the pentaethylene gycol linkers around the sodium cation, ${ }^{31}$ bringing the two aniline groups into spatial proximity.

X-ray quality crystals of the bromide salt of $\mathbf{2}$ were obtained through diffusion of diisopropyl ether into an acetonitrile solution containing additional $\mathrm{KBr}$. Subsequent single-crystal analysis confirmed the structure of the cyclic [3]catenane, with each residue of $\mathbf{C}$ linking a residue of $\mathbf{A}$ with a residue of $\mathbf{B}$ on the same side of the $\mathrm{Fe}_{6}$ plane.

The rings constituting a cyclic [3]catenane ( $6{ }_{3}^{2}$ in Alexander-Briggs-Rolfsen notation $)^{18}$ are interwoven such that if any one ring is broken, the remaining two remain interlocked. This arrangement is different to a molecular Borromean link (Fig. 3e), where upon ring fission, all three rings break apart. ${ }^{20}$ Cyclic [3]catenanes also exhibit topological chirality, in contrast to the achiral Borromean links. ${ }^{6}$ Both enantiomers of $\mathbf{2}$ were observed in the crystal, linked by a centre of inversion. 

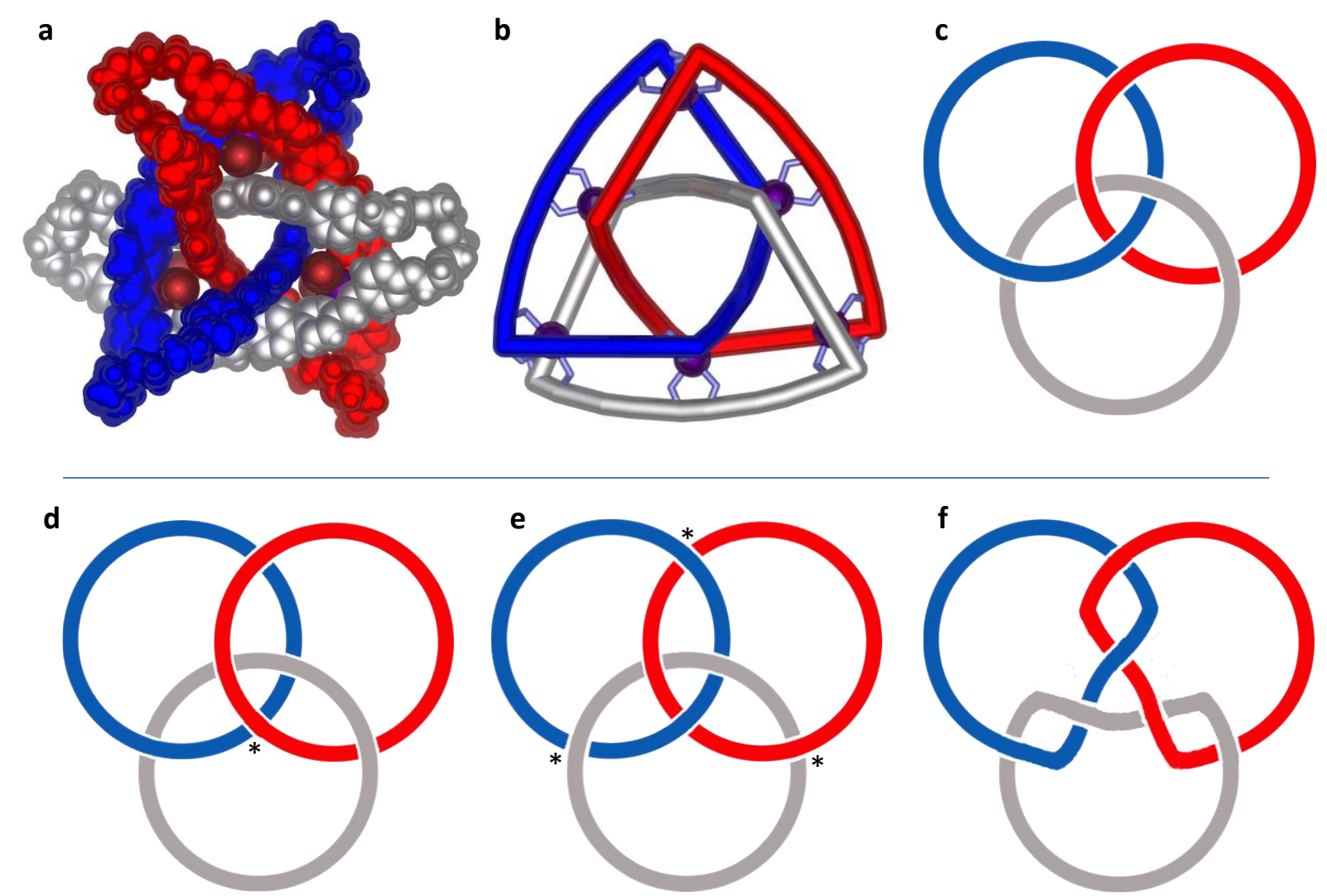

Figure 3 | Views of cyclic [3]catenane 2. (a) Space-filling representation of the crystal structure of $\mathbf{2}$ with non-coordinating anions, solvent and disorder omitted for clarity, (b) Schematic representation of $\mathbf{2}$, (c) representation of the topology of a cyclic [3]catenane. The three interlocked rings are coloured red, blue and grey. The differences in crossing points between $\mathbf{2}$ and the alternative topologies shown in (d) and (e) are highlighted with asterisks. (d) Abstract representation of a linear[3]catenane ( $4_{1}^{4}$ in Alexander-Briggs-Rolfsen notation), where the blue and red links do not interlock (e) Representation of a Borromean link $(6.3)$, (f) Representation of a closed 3 link chain $\left(6_{1}^{2}\right)$.

Finally, a fully organic, non-labile cyclic [3]catenane $\mathbf{3}$ was prepared from $\mathbf{2}$. The dynamic covalent imine linkages of $\mathbf{2}$ were rendered kinetically inert and suitable for HPLC analysis through reduction of the imine bonds to secondary amines with excess sodium borohydride, followed by demetalation using $\mathrm{Na}_{2}$ EDTA, adapting the protocol of Stoddart et al. ${ }^{32}$ The resulting yield was low due to formation of insoluble precipitates; ${ }^{32}$ however, the product could be subjected to LC-MS analysis. ${ }^{33}$ The three major components observed are the 
expected [3]catenane 3, the related [2]catenane, and the macrocycle formed from hydrolytic dethreading of the catenane during reduction (Fig. 4a). ${ }^{32}$ MS/MS analysis of the molecular ions from the peak corresponding to demetallated and reduced 3 (Fig. 4b) is consistent with the retention of its topology. On breaking one of the rings through energetic bombardment, ${ }^{34}$ the resulting MS trace (Fig. 4c) showed the presence of signals corresponding to the [2]catenane (Fig. 4c-d). Observation of this fragment is consistent with the hypothesis that the rings of the parent ion were interpenetrated in the fashion found in a [3]catenane.

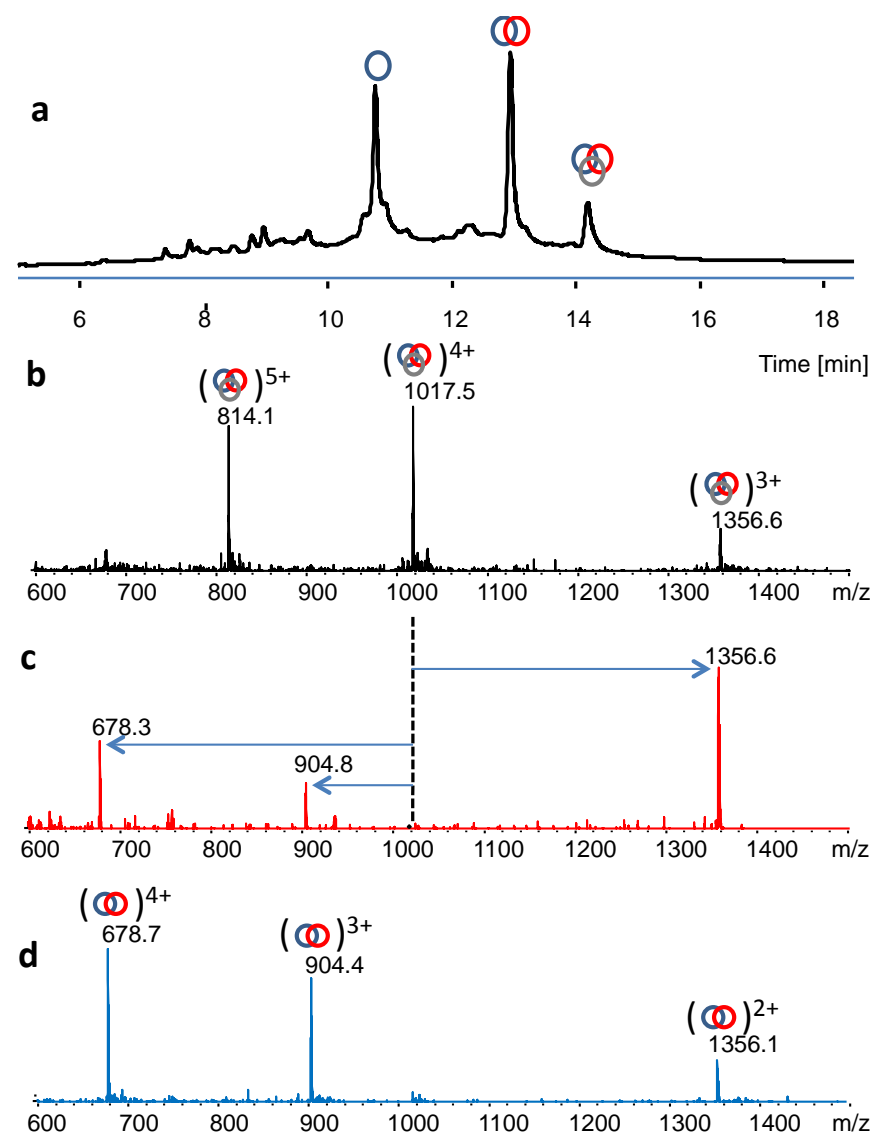

Figure 4 | HPLC-MS analysis of demetallated and reduced catenane 3. (a) HPLC trace of the mixture obtained upon reduction and demetalation of $\mathbf{2}$, with peaks corresponding to the related macrocycle, [2]catenane and [3]catenane 3, (b) MS of the peak corresponding to reduced [3] catenane 3, (c), MS/MS of the peak corresponding to the reduced [3] catenane $\mathbf{3}$, showing the formation of a [2]catenane from the rupture of one macrocycle, (d) MS of the reduced [2]catenane peak for comparison. 
The successful synthesis of both a metal-organic and fully organic cyclic [3]catenane highlights the power of selective imine exchange in the formation of mechanically interlocked structures. We envisage that this method, in conjunction with new more complex scaffolds, will allow access to new topologies that may not form using current strategies, allowing for new molecular devices that have complex topologies ${ }^{1}$ to be prepared.

\section{Methods}

\section{Synthesis of $[1]\left(\mathrm{BF}_{4}\right)_{6}$}

[3,3'6',2"5",3'"-quaterpyridine]-6,6'"-dicarbaldehyde A (30.5 mg, 83.3 Hmol, 3 equiv.), [3,3'bipyridine]-6,6'-dicarbaldehyde $\mathbf{B}(17.7 \mathrm{mg}, 83.3 \mu \mathrm{mol}, 3$ equiv. $)$ and $\mathrm{Fe}\left(\mathrm{BF}_{4}\right)_{2} \cdot 6 \mathrm{H}_{2} \mathrm{O}(56.3$, $166.6 \mu$ mol, 6 equiv.) were suspended in $\mathrm{CH}_{3} \mathrm{CN}(20 \mathrm{~mL})$ and heated at $70{ }^{\circ} \mathrm{C}$ in a PTFE stoppered Schlenk tube until all the solids dissolved and a dark red solution was obtained. A solution of 4-chloroaniline in $\mathrm{CH}_{3} \mathrm{CN}$ (2.78 mL, $0.12 \mathrm{mM}, 12$ equiv.) was added followed by the dropwise addition of tetra-n-butylammonium bromide in $\mathrm{CH}_{3} \mathrm{CN}(3.47 \mathrm{~mL}, 0.048 \mathrm{mM}, 6$ equiv.). The reaction mixture was stirred at $70{ }^{\circ} \mathrm{C}$ for 36 hours. The solution was filtered through a PTFE syringe filter ( $4.5 \mu \mathrm{m}$ pore size) and subsequent addition of diethyl ether (30 $\mathrm{mL})$ precipitated out $[\mathbf{1}]\left(\mathrm{BF}_{4}\right)_{6}$ as a green solid that was isolated by centrifugation $(111 \mathrm{mg}$, $91 \%)$.

${ }^{1} \mathrm{H}$ NMR (400 MHz, $\left.298 \mathrm{~K}, \mathrm{CD}_{3} \mathrm{CN}\right): \delta 198.37,186.43 \mathrm{br}, 49.04,25.68,19.29,14.81,13.66$, 13.04, 10.87, 9.32, 8.30, 7.06, 6.60, 5.75, 4.65. ${ }^{19} \mathrm{~F}$ NMR $\left(376 \mathrm{MHz}, 298 \mathrm{~K} \mathrm{CD}{ }_{3} \mathrm{CN}\right.$, reference $\left.\mathrm{C}_{6} \mathrm{~F}_{6}\right): \delta 150.99\left(\mathrm{BF}_{4}^{-}\right)$. Further assignments were hampered by the paramagnetic nature of the complex. ESI-MS: $\mathrm{m} / \mathrm{z}: 643.969[1]^{6+}, 790.208[1]\left(\mathrm{BF}_{4}\right)_{1}{ }^{5+}, 1009.519$ $[1]\left(\mathrm{BF}_{4}\right)_{2}{ }^{4+}, 1374.550[1]\left(\mathrm{BF}_{4}\right)_{3}{ }^{3+}$. Elemental analysis: C, 46.10; H, 2.85; N, 9.06. Required $[1]\left(\mathrm{BF}_{4}\right)_{6} \cdot 8 \mathrm{H}_{2} \mathrm{O}: \mathrm{C}, 46.14 ; \mathrm{H}, 2.89 ; \mathrm{N}, 9.28$.

Green crystals of $[\mathbf{1}]\left(\mathrm{ClO}_{4}\right)_{5}\left(\mathrm{FeBr}_{4}\right)_{0.5} \cdot 10 \mathrm{CH}_{3} \mathrm{CN} \cdot \mathrm{H}_{2} \mathrm{O}$ suitable for X-ray diffraction studies were grown by slow diffusion of diisopropyl ether into an acetonitrile solution of the perchlorate salt of $\mathbf{1}$ (see Supplementary Information) over several days and were used directly in analysis. X-ray analyses are detailed in the Supplementary Information.

\section{Synthesis of $[2]\left(\mathrm{BF}_{4}\right)_{6}$}


A $1.86 \mathrm{mM}$ solution of $[\mathbf{1}]\left(\mathrm{BF}_{4}\right)_{6}$ in $\mathrm{CH}_{3} \mathrm{CN}(8.2 \mathrm{ml}, 15.3 \mathrm{mmol}, 1$ equiv.) was added to a stirred solution of $\mathbf{C}(41.7 \mathrm{mg}, 99.1 \mu \mathrm{mol}, 6.5$ equiv.) and $\mathrm{NaBr}(25 \mu \mathrm{L}, 0.62 \mathrm{M}, 1$ equiv.) in $2 \mathrm{~mL} \mathrm{CH}_{3} \mathrm{CN}$. The solution was degassed by three freeze-pump-thaw cycles and then heated at $70{ }^{\circ} \mathrm{C}$ for 5 days. The solution was filtered through a $4.5 \mu \mathrm{M}$ PTFE syringe filter and the complex precipitated out by the addition of diethyl ether : hexanes $(1: 1,30 \mathrm{~mL})$. The resulting dark green solid was isolated by centrifugation and the remaining solvent removed in vacuo $(65 \mathrm{mg}, 79 \%)$.

${ }^{1} \mathrm{H}$ NMR (400 MHz, $\left.\mathrm{CD}_{3} \mathrm{CN}\right) \delta 191.98,179.98$ br, 48.36, 25.68, 17.83, 13.80, 13.01, 8.76, $8.11,7.16,6.67,6.59,6.15,5.46,5.30,5.07,4.74,4.59,4.43,4.34,4.14,3.65,3.58,1.15{ }^{19} \mathrm{~F}$ NMR (376 MHz; $\mathrm{CD}_{3} \mathrm{CN}$, reference $\left.\mathrm{C}_{6} \mathrm{~F}_{6}\right)$ : $\delta 151.04\left(\mathrm{BF}_{4}{ }^{-}\right)$. Further assignments were hampered by the paramagnetic nature of the complex. ESI-MS: m/z: $809.578\left[2 \cdot \mathrm{Br}_{6}\right]^{6+}$, $988.620[2]\left(\mathrm{BF}_{4}\right)_{1}{ }^{5+}, 1257.096[2]\left(\mathrm{BF}_{4}\right)_{2}{ }^{4+}$. Elemental analysis: C, 50.23; H, 4.34; N, 7.23. Required [2] $\left(\mathrm{BF}_{4}\right)_{6} 12 \mathrm{H}_{2} \mathrm{O}: \mathrm{C}, 50.24 ; \mathrm{H}, 4.65 ; \mathrm{N}, 7.51$.

A variety of crystallisation conditions were screened including the use of different $\mathrm{Fe}^{\mathrm{II}}$ salts in the synthesis of $\mathbf{2}$, and the addition of different group 1 and 2 salts as detailed in section 1.10 of the Supplementary Information. Green crystals of $[2](\mathrm{Br})_{6} \cdot 0.75 \mathrm{KBr} \cdot 6.25 \mathrm{H}_{2} \mathrm{O}$ suitable for X-ray diffraction studies were grown by slow diffusion of diisopropyl ether into an acetonitrile solution of [2] $\left(\mathrm{BF}_{4}\right)_{6}$ containing $\mathrm{KBr}$ over several days and were used directly in analysis. X-ray analyses are detailed in the Supplementary Information.

\section{References}

1 Evans, N. H. \& Beer, P. D. Progress in the synthesis and exploitation of catenanes since the Millennium. Chem. Soc. Rev. 43, 4658-4683, (2014).

2 Forgan, R. S., Sauvage, J. P. \& Stoddart, J. F. Chemical topology: complex molecular knots, links, and entanglements. Chem. Rev. 111, 5434-5464, (2011).

3 Beves, J. E., Blight, B. A., Campbell, C. J., Leigh, D. A. \& McBurney, R. T. Strategies and tactics for the metal-directed synthesis of rotaxanes, knots, catenanes, and higher order links. Angew. Chem. Int. Ed. 50, 9260-9327, (2011). 
4 Ponnuswamy, N., Cougnon, F. B., Clough, J. M., Pantos, G. D. \& Sanders, J. K. Discovery of an organic trefoil knot. Science 338, 783-785, (2012). van Dongen, S. F., Cantekin, S., Elemans, J. A., Rowan, A. E. \& Nolte, R. J. Functional interlocked systems. Chem. Soc. Rev. 43, 99-122, (2014).

6 Liang, C. Z. \& Mislow, K. Topological chirality and achirality of links. J. Math. Chem. 18, 1-24, (1995).

7 Dean, F. B. \& Cozzarelli, N. R. Mechanism of strand passage by Escherichia coli topoisomerase I. The role of the required nick in catenation and knotting of duplex DNA. J. Biol. Chem. 260, 4984-4994, (1985).

8 Takusagawa, F. \& Kamitori, S. A real knot in protein. J. Am. Chem. Soc. 118, 89458946, (1996).

9 Rosengren, K. J. et al. Microcin J25 has a threaded sidechain-to-backbone ring structure and not a head-to-tail cyclized backbone. J. Am. Chem. Soc. 125, 1246412474, (2003).

10 Duda, R. L. Protein chainmail: catenated protein in viral capsids. Cell 94, 55-60, (1998).

11 Quake, S. R. Topological effects of knots in polymers. Phys. Rev. Lett. 73, 33173320, (1994).

12 Saitta, A. M., Soper, P. D., Wasserman, E. \& Klein, M. L. Influence of a knot on the strength of a polymer strand. Nature 399, 46-48, (1999).

13 Sauvage, J. P. Interlacing molecular threads on transition-metals - catenands, catenates, and knots. Acc. Chem. Res. 23, 319-327, (1990).

14 Ashton, P. R. et al. A [2]catenane made to order. Angew. Chem. Int. Ed. Engl. 28, 1396-1399, (1989).

15 Hunter, C. A. Synthesis and structure elucidation of a new [2]-catenane. J. Am. Chem. Soc. 114, 5303-5311, (1992).

16 Nierengarten, J. F., Dietrichbuchecker, C. O. \& Sauvage, J. P. Synthesis of a doubly interlocked [2]-catenane. J. Am. Chem. Soc. 116, 375-376, (1994).

17 Mohr, B., Weck, M., Sauvage, J. P. \& Grubbs, R. H. High-yield synthesis of [2]catenanes by intramolecular ring-closing metathesis. Angew. Chem. Int. Ed. Engl. 36, 1308-1310, (1997). 
18 Lincheneau, C., Jean-Denis, B. \& Gunnlaugsson, T. Self-assembly formation of mechanically interlocked [2]- and [3]catenanes using lanthanide ion [Eu(III)] templation and ring closing metathesis reactions. Chem. Commun. 50, 2857-2860, (2014).

19 Leigh, D. A., Pritchard, R. G. \& Stephens, A. J. A Star of David catenane. Nature Chem. 6, 978-982, (2014).

20 Chichak, K. S. et al. Molecular Borromean rings. Science 304, 1308-1312, (2004).

21 Ayme, J. F. et al. A synthetic molecular pentafoil knot. Nature Chem. 4, 15-20, (2012).

22 Hasenknopf, B., Lehn, J. M., Kneisel, B. O., Baum, G. \& Fenske, D. Self-assembly of a circular double helicate. Angew. Chem. Int. Ed. Engl. 35, 1838-1840, (1996).

23 Allen, K. E. et al. Head-to-tail and heteroleptic pentanuclear circular helicates. Angew. Chem. Int. Ed. 49, 6655-6658, (2010).

24 Safont-Sempere, M. M., Fernandez, G. \& Wurthner, F. Self-sorting phenomena in complex supramolecular systems. Chem. Rev. 111, 5784-5814, (2011).

25 Ayme, J. F., Beves, J. E., Campbell, C. J. \& Leigh, D. A. The self-sorting behavior of circular helicates and molecular knots and links. Angew. Chem. Int. Ed. 53, 78237827, (2014).

26 Kramer, R., Lehn, J. M. \& Marquis-Rigault, A. Self-recognition in helicate selfassembly: spontaneous formation of helical metal complexes from mixtures of ligands and metal ions. Proc. Natl. Acad. Sci. U.S.A. 90, 5394-5398, (1993).

27 Riddell, I. A. et al. Five discrete multinuclear metal-organic assemblies from one ligand: deciphering the effects of different templates. J. Am. Chem. Soc. 135, 2723 2733, (2013).

28 Sarma, R. J. \& Nitschke, J. R. Self-assembly in systems of subcomponents: simple rules, subtle consequences. Angew. Chem. Int. Ed. 47, 377-380, (2008).

29 De, S., Mahata, K. \& Schmittel, M. Metal-coordination-driven dynamic heteroleptic architectures. Chem. Soc. Rev. 39, 1555-1575, (2010).

30 Schultz, D. \& Nitschke, J. R. Designing multistep transformations using the Hammett equation: imine exchange on a copper(I) template. J. Am. Chem. Soc. 128, 9887-9892, (2006). 
31 Tung, S. T., Lai, C. C., Liu, Y. H., Peng, S. M. \& Chiu, S. H. Synthesis of a [2]catenane from the sodium ion templated orthogonal arrangement of two diethylene glycol chains. Angew. Chem. Int. Ed. 52, 13269-13272, (2013).

32 Peters, A. J., Chichak, K. S., Cantrill, S. J. \& Stoddart, J. F. Nanoscale Borromean links for real. Chem. Commun., 3394-3396, (2005).

33 Chung, M.-K., Severin, K., Lee, S. J., Waters, M. L. \& Gagné, M. R. Constitutionally selective amplification of multicomponent 84-membered macrocyclic hosts for (-)cytidine•H+. Chem. Sci. 2, 744, (2011).

34 Dietrich-Buchecker, C., Leize, E., Nierengarten, J.-F., Sauvage, J.-P. \& Van Dorsselaer, A. Singly and doubly interlocked [2]-catenanes: influence of the degree of entanglement on chemical stability as estimated by fast atom bombardment (FAB) and electrospray ionization (ESI) mass spectrometries (MS). J. Chem. Soc., Chem. Commun., 2257, (1994).

\section{Acknowledgements}

This work was supported by the UK Engineering and Physical Sciences Research Council (EPSRC) and a Marie Curie fellowship for JJH (ITN-2010-264645). We thank Diamond Light Source (UK) for synchrotron beamtime on I19 (MT7984 and MT8464).

\section{Author Contributions}

JRN and CSW conceived and designed the experiments. CSW performed the experiments and analysed the data. TKR and JJH collected the X-ray data and refined the structures. AB and CSW carried out the HPLC analysis. All authors discussed the results and edited the manuscript

\section{Additional Information}

Crystallographic data have been deposited with the CCDC (numbers 1022470-1022473). Reprints and permissions information is available at www.nature.com/reprints. The authors declare no competing financial interests. Supplementary information and chemical compound information accompany this paper at www.nature.com/naturechemistry. Correspondence and requests for materials should be addressed to JRN. 


\section{Competing financial interests}

The authors declare no competing financial interests 